\title{
Performance Analysis of SPWM and SVPWM Inverters Fed Induction Motor
}

\author{
Sameer Ibraheem Abood \\ Assistant Lecturer \\ Institute of Technology-Baghdad
}

\begin{abstract}
This paper presents the analysis of the sinusoidal pulse width modulation (SPWM) and space-vector modulation (SVPWM). The analysis involves the relationship between modulation signals and space vectors and the switching patterns of spacevector modulation and the trigger of power electronic device .All the relationships provides a bidirectional bridge for the transformation between sinusoidal PWM modulators and space-vector modulation modulators. It is noted that all the drawn conclusions are independent of the load type. Nevertheless, the implementations of both SPWM and SVPWM circuits are carried out using three phase induction motor as a load.
\end{abstract}

Index Terms-SPWM, SVPWM, Induction Motors, D.C link converters ,PSIM.

\section{INTRODUCTION}

The technique of PWM is found to be widely applied for generating appropriate converter control gating signals. These are originally generated using advanced electronic circuits. More recently, microcomputers and microcontrollers have dominated the design of control signal generators. PWM generators are widely used in power electronics circuit design for controlling the electronic switching of power inverters. This is because of the capability of controlling voltage, frequency and harmonic content in a single power stage.

There are various techniques to control the inverter gain. The most efficient method of controlling the gain (hence the output voltage) is to incorporate (PWM) control with the inverters.

The most commonly used techniques are:

i-Single pulse width modulation.

ii-Multiple pulse width modulation.

iii-Sinusoidal pulse width modulation.

iv-Modified Sinusoidal pulse width modulation.

v-Phase- displacement control.

vi-Space vector pulse width modulation.

In a speed control systems, with a wide range of generated frequencies, a microprocessor is used to generate PWM or a six-step un modulated signal.

\author{
Mohammed Sabri A. Raheem \\ Assistant Professor \\ College of Electrical and Electronics Tech.- Baghdad
}

\section{BASIC METHODOLOGY}

The basic idea of the induction motor speed control in the modern technologies is to use rectifier circuits to convert the A.C. supply energy to a D.C. system \& via D.C. link circuits $[1,2]$ fed to an inverter circuits, which are of different criteria's, to produce a variable frequency, voltage , or both , IM control parameters as shown in figure(1).

This will lead to the presence of a more reliable speed control criteria's than the Classical speed control methods.

The main methods whose operating analysis are presented \& compared in this paper are:

1-The Sine Pulse Width Modulation.

2-The Space Vector PWM.

\subsection{Types of AC Drive}

The two basic voltage inverter systems are the pulse width modulation PWM inverter and the six-step voltage source inverter VSI. A typical PWM system is illustrated in Figure (1-a). The input converter is usually a diode bridge rectifier, which provides a constant voltage.

Variable output voltage is achieved by pulse width modulation of the constant filtered DC bus voltage, which is the basis for the drive name. The VSI is shown in Figure (1b). The input converter in this case must provide a variable DC bus voltage, which is again filtered by a capacitor which is usually larger than in a PWM since it filters a larger ripple as well as providing a portion of the inverter section simply inverts the variable $\mathrm{DC}$ bus voltage to provide the AC output.

In current-type inverter the $\mathrm{AC}$ motor current is directly controlled, and the output voltage is determined by the properties of the motor. The current source inverter CSI illustrated in Figure (1-c). The input converter provides a variable DC bus voltage, which is filtered by an inductor that is large enough to provide an essentially constant DC current over the period of a cycle of the output. This DC current is then inverted into variable-frequency AC current. Voltage control is accomplished by adjusting the DC current to achieve the desired output AC voltage [3]. 


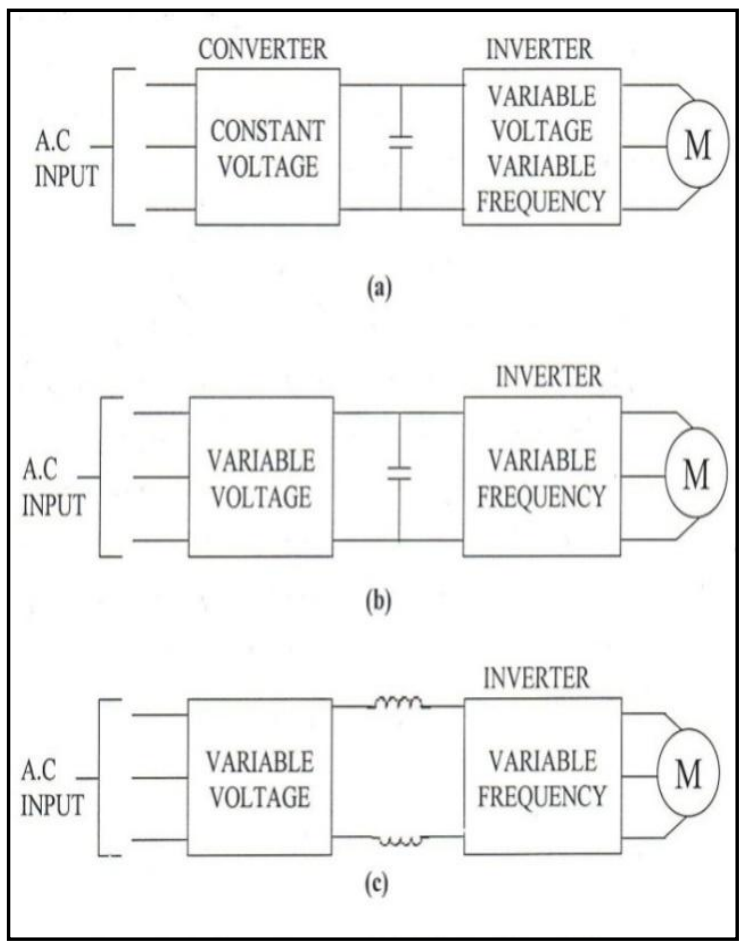

Fig. (1) Block diagrams (a) PWM

(b)VSI

(c) CSI

\subsection{3- Phase (VSI) circuits}

The power circuit of a three-phase voltage source inverter is shown in Figure (3). It consists of six self-commutated semiconducter switches $S_{1}$ to $S_{6}$ with antiparallel or feedback diodes $D_{1}$ to $D_{6}$. They may be realized by using thyristors, gate-turn-off thyristors (GTO's), power transisters, metaloxide-semiconductor field effect transistors (MOSFETs) or insulated gate bipolar transistors (IGBTs). The motor, which is connected across terminals $\mathrm{A}, \mathrm{B}$, and $\mathrm{C}$ may have star or delta connection.This inverter can be operated as six-step inverter or as a Pulse Width Modulated (PWM ) inverter[4,5].

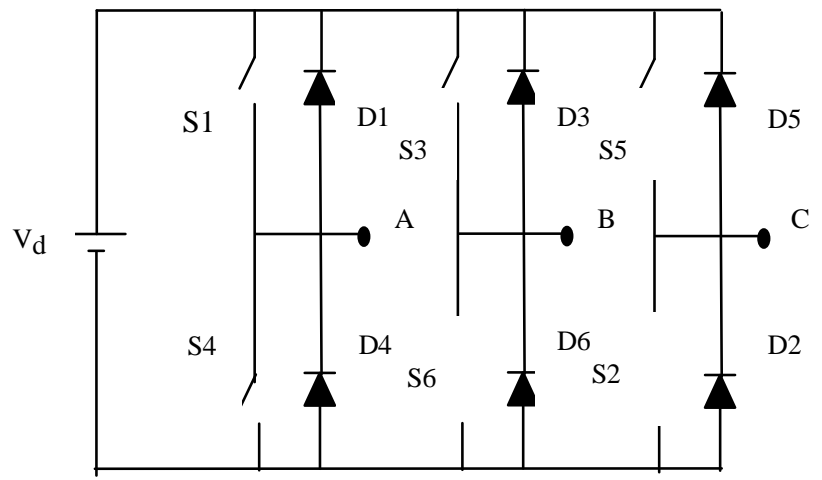

Fig. (2) Three-phase voltage source inverter

\subsection{3-Phase Six-Step Inverter}

The three-phase six-step, or quasi-square-wave inverter is a voltage source inverter that has been widely used in commercial adjustable-speed AC motor drive. As shown in

Figure (2) the output terminals A, B, C are connected to a three-phase AC motor. A reversal of the direction of motor rotation is readily accomplished by changing the inverter output phase sequence by means of the firing angle [6]. The control signals for the six switches in the inverter in Figure (2), $I_{g 1}$ to $I_{g 6}$ are shown in Figure (3).

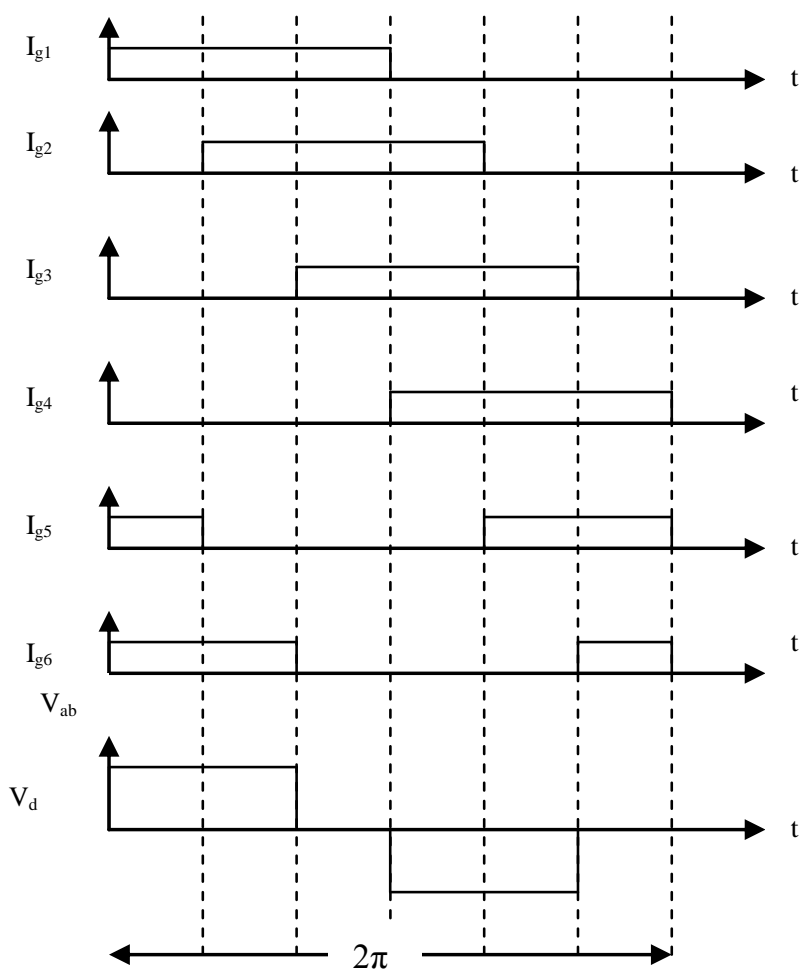

Fig. (3) gates and line voltage of mode $180^{\circ}$.

\subsection{Sinusoidal PWM}

This type of modulation is commonly used in industrial application as SPWM. The frequency of reference signal fr determines the inverter output frequency fo, and its peak amplitude Ar controls the modulation index $\mathrm{M}$, and then in turn rms output voltage Vo. The number of pulses per half cycle depends on the carrier frequency within the constraint that two transistors of the same arm (S1 and S4) cannot conduct at the same time, the instantaneous output voltage is shown in Figure (4-a). The same gating signals can be generated by using unidirectional triangular carrier wave as shown in figure (4-b).

Fourier analysis shows that the amplitudes of the harmonic voltages may be expressed in terms of the switching or commutation angles $\alpha 1, \alpha 2, \alpha 3 \ldots$ If the waveform has quarter-wave and half-wave symmetry, as shown, the amplitude of the kth harmonic voltage is Vk: 


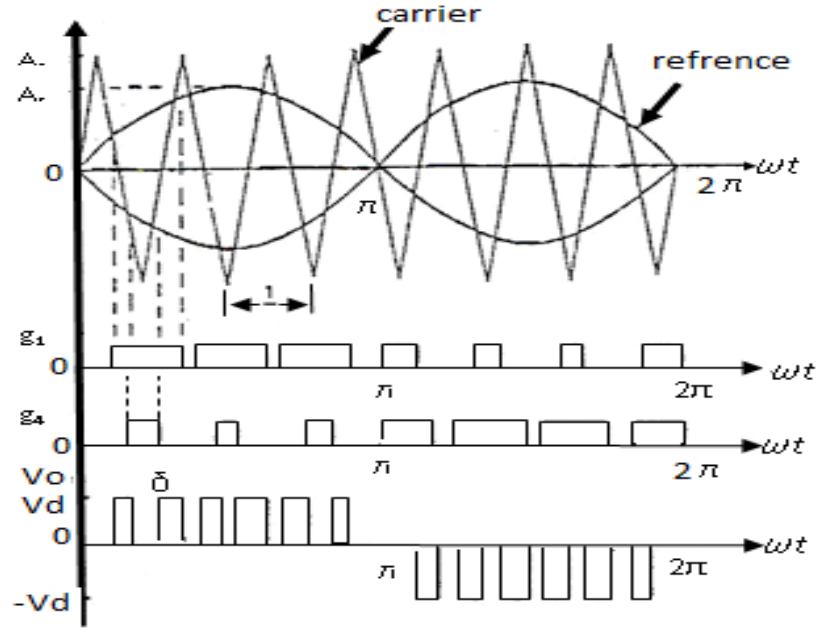

Fig.(4) Sinusoidal pulse-width modulation

$v_{k}=\frac{2 v_{d}}{k \pi}\left\{1+2 \sum_{i=1}^{m}(-1)^{i} \operatorname{Cos} k \alpha_{i}\right\}$

Where $\mathrm{m}$ is the number of switching angles per quarter-cycle are as in equation (2):

$$
V_{O}=\operatorname{Vs}\left(\sum_{m=1}^{2 p} \frac{\sin }{\pi}\right)^{1 / 2}
$$

\subsection{Space Vector PWM}

Space vector modulation (SVM) is quite different from the PWM methods. With PWMs. SVM, however treats the inverter as a single unit; specifically the inverter can be driven to eight unique states as shown in fig.5 Modulation is accomplished by switching the state of the inverter. The control strategies are implemented in digital systems SVM is a digital modulating technique where the objective is to generate PWM load line voltages that are in average equal to a given load line voltages. This is done in each sampling period by properly selecting the switch states of the inverter and the calculation of the appropriate time period for each states. The selection of the states and their time periods are accomplished by the space vector (SV) transformation.

\section{COMPUTER SIMULATION \& DIGITAL CONTORL}

Simulation studies of power electronic circuits with PSPICE are very simple to conduct. They basically consist of three steps (1) creation of circuit schematic, (2) simulation, and (3) graphical plotting of the results. The programs required in these steps parts, such as voltage and current sources, resistors, capacitors, op. amps, and gates, and power devices, such as diodes, power MOSFETs, and IGBTs, are brought in from the parts library with their symbols, attributes, and models and then interconnected to generate the complete schematic. A simulation command is used to start the simulation using PSIM. The Stimulus Editor is a graphical input waveform editor that generates the time-domain waves to test the circuit's response during simulation.

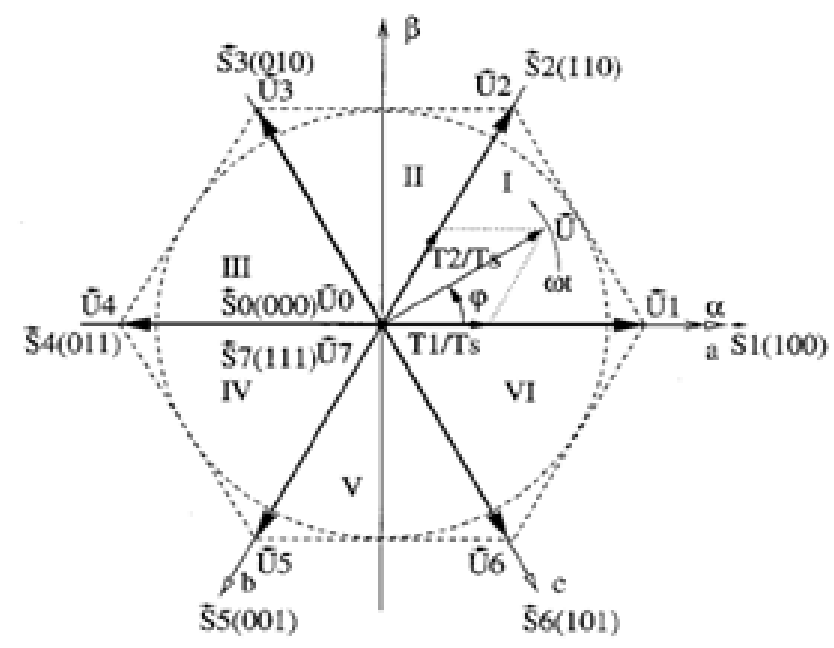

Fig. (5). Voltage Space vectors

Finally, when the analysis results are generated, the Probe software plots the waveforms from the output data. The waveforms help to refine the circuit design as shown until satisfactory waveforms are obtained from the optimized circuit design.

A flowchart for the steps of advanced drive control development is given in figure (7) .It is assumed that the machine with the converter and local controller design already exists.

Table(1) Line and phase voltages of the eight space vector

\begin{tabular}{|c|c|c|}
\hline Space vector & Vqd-line & Vqd-phase \\
\hline $\mathrm{Vo}(000)$ & 0 & 0 \\
\hline V1(100) & $\frac{2}{\sqrt{3}} \mathrm{Vd} \mathrm{e}^{\mathrm{j} 30^{\circ}}$ & $\frac{2}{3} \mathrm{Vd} \mathrm{e}^{\mathrm{j} 0^{\circ}}$ \\
\hline V2(110) & $\frac{2}{\sqrt{3}} \mathrm{Vd} \mathrm{e}^{\mathrm{j} 90^{\circ}}$ & $\frac{2}{3} V d e^{j 60^{\circ}}$ \\
\hline V3(010) & 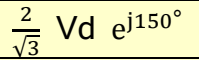 & $\frac{2}{3} \mathrm{Vd} \mathrm{e}^{\mathrm{j} 120^{\circ}}$ \\
\hline V4(011) & $\frac{2}{\sqrt{3}} V d e^{j 210^{\circ}}$ & $\frac{2}{3} \mathrm{Vd} \mathrm{e}^{\mathrm{j} 180^{\circ}}$ \\
\hline V5(001) & $\frac{2}{\sqrt{3}} \operatorname{Vd~} \mathrm{e}^{\mathrm{j} 270^{\circ}}$ & $\frac{2}{3} V_{d} \mathrm{e}^{\mathrm{j} 240^{\circ}}$ \\
\hline V6(101) & $\frac{2}{\sqrt{3}} V d e^{j 330^{\circ}}$ & $\frac{2}{3} V_{d} e^{j 300^{\circ}}$ \\
\hline V7(111) & 0 & 0 \\
\hline
\end{tabular}

In the beginning, the drive control strategy is formulated based on the performance specs of the system. The drive system is then analyzed and control algorithms are developed in detail. However, to have full realization in the performance of a newly developed controller, it is necessary to perform simulation studies of the whole drive system and modify the control strategy and its parameters as needed. Mathematical models of the converter, machine, and controller are developed and simulation studies are conducted with these models. After the simulation performance is optimized, a prototype drive and its controller hardware and software are designed, built, and tested to finalize the design. 


\section{INDUCTION MOTOR DATA}

The parameters of the tested induction motor are listed below knowing that all parameters are referred to the stator side.

Both machine models are symmetrical and are connected in $\mathrm{Y}$ on the stator.

3-phase symmetrical squirrel-cage induction

Rs : Stator winding resistance, $0.294 \mathrm{Ohm}$

Ls: Stator winding leakage ind., $1.39 \mathrm{H}$

Rr: Rotor winding resistance, $0.156 \mathrm{Ohm}$

$\mathrm{Lr}$ :Rotor winding leakage ind., $0.74 \mathrm{mH}$

Lm :Magnetizing inductance, $41 \mathrm{mH}$

No. of Poles $\mathrm{P}=6$

Moment of inertia $\mathrm{J}=0.4$ in $\mathrm{kg} * \mathrm{~m} 2$

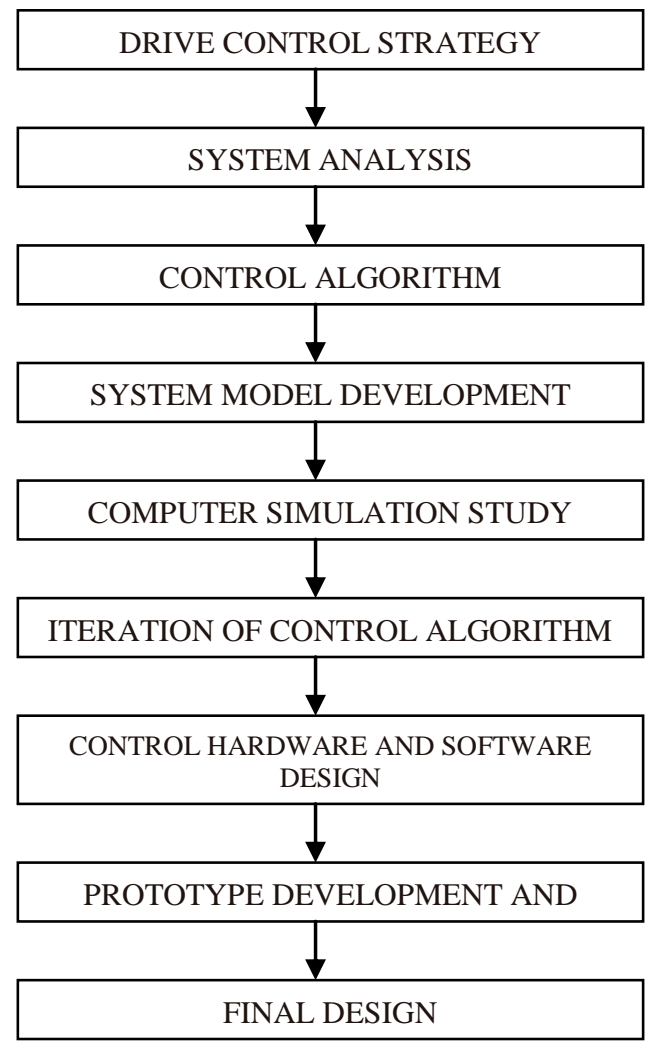

Fig.(6) Flowchart for prototype ac drives control development with a simulation study.

\section{SIMULATION RESULTS}

\section{1 simulated SPWM \& SVPWM}

The schematic diagram of the simulated constructed system is shown in Figure (7)
AC motor drive using PWM, and Figures (8) illustrates the AC motor drive using state space vector. The output phase voltage of 380 volt at frequency $50 \mathrm{~Hz}$.

Figures (7) and (8), show the PWM pulses used to control the lower and upper MOSFET of power circuit via drive. The variation of duty cycles and the phase shift between $\mathrm{ON}$ and OFF periods, and which is resulted from dividing frequency by two.

The followings notes can be recorded:

The percentage reduction of total harmonic distortion for voltage (THDV) and current (THDI) are the same approximately the values calculated in simulation.

The waveforms obtained practically, as shown in Figures (9) and (10), are measured by using a universal scope meter and are transferred to computer software system On comparing the simulated circuit output waveforms coincidence between the waveforms of the practical and simulated waveforms can be noticed.

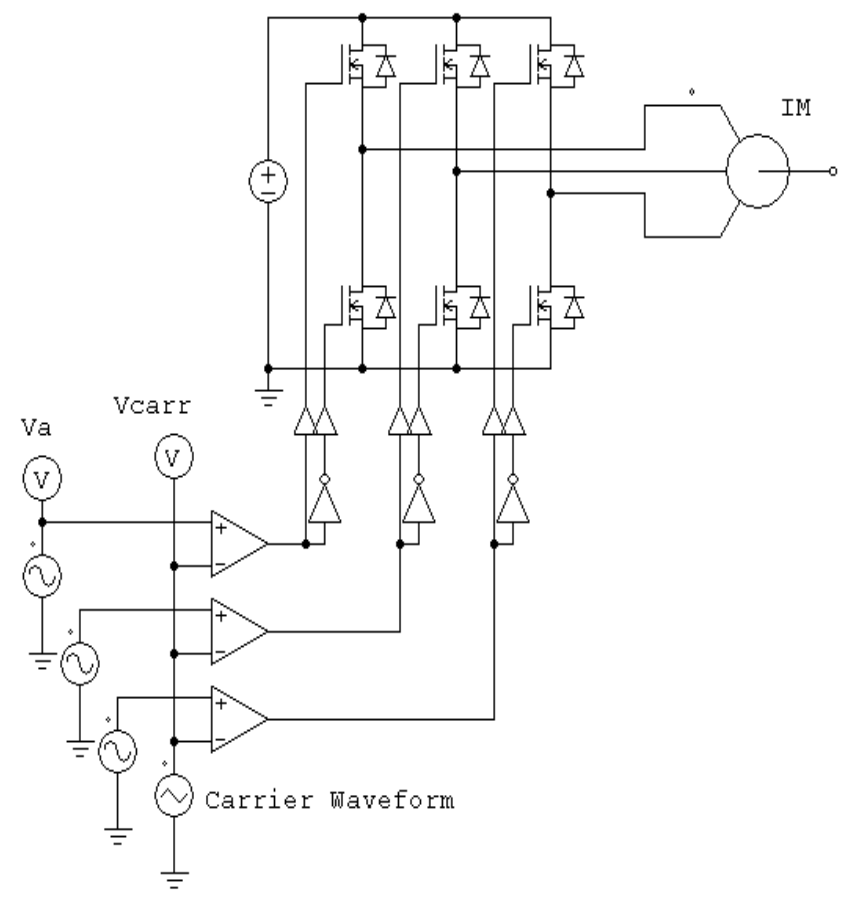

Fig.(7) AC motor drive using SPWM 


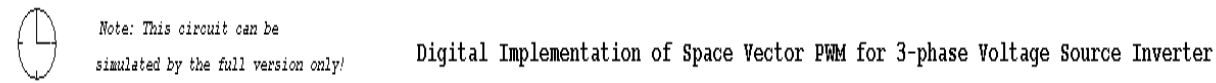

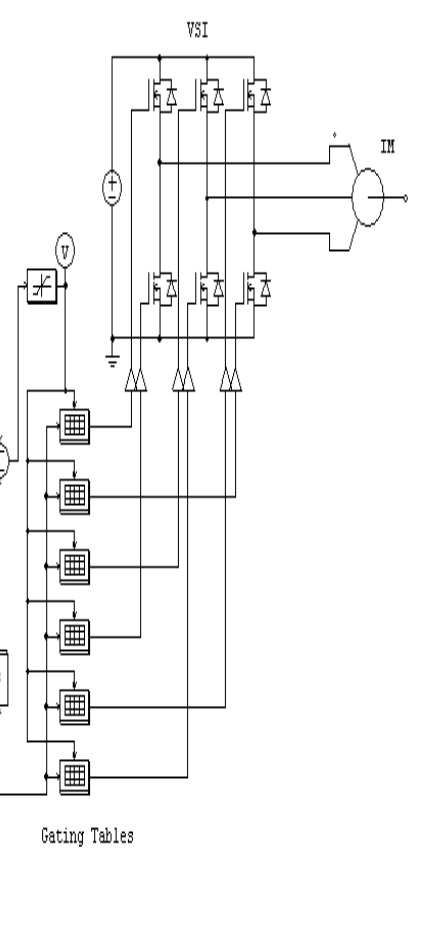

Fig.(8) AC motor drive using SVPWM
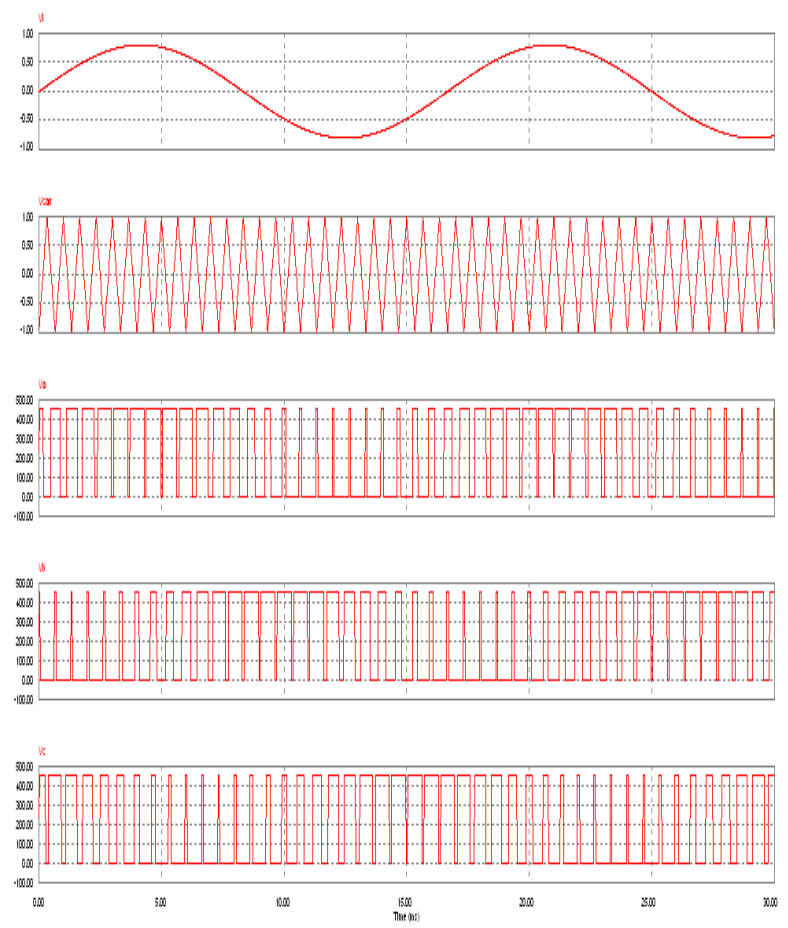

Fig.(9) Output waveform AC Motor drive using SPWM
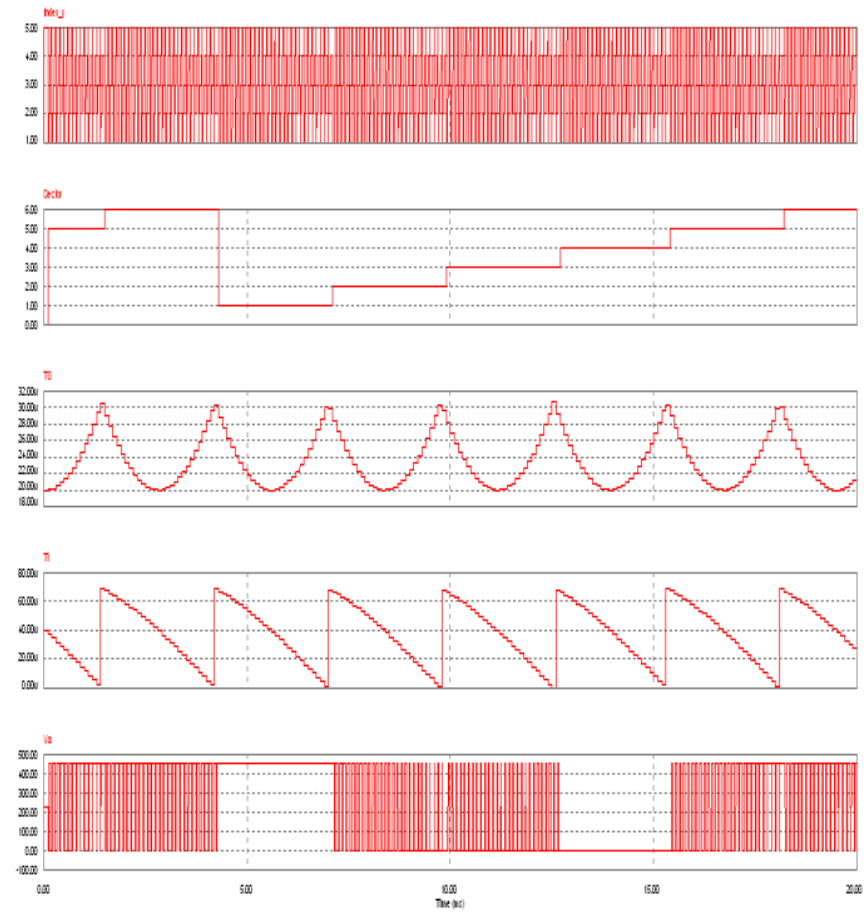

Fig.(10) Output waveform AC motor drive using SVPWM 


\subsection{Advantages of the simulated system}

The general advantage of the output design can be recorded as the following:

1-PSIM program is very simple, accurate, and effectiveness for output design.

2-It can be easily applied for any types of transistors.

3-It can be used for any different modulation technique which produces different inverter output.

4-This design method can be extended to any rating of similar drive system especially in industrial application.

5-Generates less harmonic distortion in output current and voltage in the winding of motor.

6-Provides more efficient use DC supply voltage.

\section{CONCLUSIONS}

In this paper, the performance analysis of the SPWM and SVPWM modulation was comprehensively investigated.

All the relationships provide a universal platform not only to implement Transformation between carrier-based PWM and space-vector modulation, but also to develop different performance PWM modulators. All the analyses are independent of the load type. It indicates that the possible maximum modulation index for all SPWM modulators is in the linear modulation range.

Furthermore, the problem of feedback SPWM was highlighted with corresponding solutions.

\section{REFRENCES}

[1] Bimal K. Bose,"Power Electronics and Motor Drives, Advances and Trends,by: Based Expert System Using Object Oriented Programming Language" ,2006.

[2] Ahmed Cheriti, Kamal Al-Haddad, "A Rugged Soft Commutated PWM Inverter for AC Drives", IEEE Transactions on Power Electronics, Vol.7, No.2, pp. 385402, April 1992.

[3] Mariusz Malinowski, "Sensorless Control Strategies for Three-Phase PWM Rectifiers", PhD Thesis Warsaw University of Technology, Poland. 2001.

[4] Jamal A Mohammed, "Performance Improvement of Induction Motor Fed by an Inverter using Harmonic elimination technique", M.SC Thesis submitted to the Department of Technical Education, Iraq. 2002.

[5] Kareem A. Hamad, "Harsh Environment with Very Low Harmonics Distortion Three Phase Speed Controller", $\mathrm{PhD}$ Thesis Submitted to the Department of Electrical and Electronic Engineering, University of Technology, Iraq. 2004.

[6] S. B. Dewan, G. R. Slemon, A. Straughen, "Power Semiconductor Drives", john Wiley \& Sons. Inc, New York, 1984

[7] J.M. Murphy, F. G.Turnbull, "Power Electronic Control of AC Motors", First edition, by A. Wheaton and Co. Ltd, Exeter, Great Britain, 1988.

[8] M. H. Rashid, "Power Electronic, Circuits, Devices, and Applications", Second Edition, Printice-Hall of India, New Delhi, 1994. 